\title{
Effectiveness of Lecture-Simulation-Combined Palliative Care Course to Improve Nursing Students' Knowledge, Attitude and Coping
}

\author{
Yan Wang
}

\begin{abstract}
Palliative care education for undergraduate nursing students varies in hours, methods, and contents worldwide. This study aimed to examine the nursing students' changes in palliative care knowledge, attitude, and coping with death after 18 hours of lecture-simulation-combined palliative care course. The study adopted a quasi-experiment method by one-group pre-posttest design. The palliative care course was composed of 2-hour of lecture, 10-hour of lecture-simulation-combined terminal symptoms learning, and 6-hour of simulation scenario practice. Students' knowledge was measured with Palliative Care Quiz for Nursing, students' attitude was measured with Frommelt Attitude towards Care of the Dying, and students' coping with death was measured with Coping with Death Scale before and after the palliative care course. There were 52 nursing undergraduate students participated in this study. The higher mean score of Palliative Care Quiz for Nursing, Frommelt Attitude towards Care of the Dying, and Coping with Death Scale gained after the course indicated students' improved knowledge, attitude, and coping $(P<0.05)$. Results from multiple regression analysis showed that knowledge and attitude had statistically significant impacts on students' coping with death $(P<0.05)$. The palliative care course combining lectures with simulation-based learning could improve nursing students' palliative care knowledge, attitude, and coping strategies. Nursing educators can improve nursing students' coping with death by enriching their knowledge and improving their attitude.
\end{abstract}

Index Terms-Palliative care, attitude, coping, knowledge, lecture-simulation-combined, nursing students.

\section{INTRODUCTION}

As the population ages, the need for palliative care as a part of continuous health care increases. Nurses should be prepared to care for clients throughout their entire lifespan, including delivering palliative care at the last stage of life. Nurses play a crucial role in the palliative care team since they spend the longest time with patients [1]. Providing palliative care is a challenging and anxiety-provoking duty because of incurable diseases and impending death. Still, the undergraduate nursing curriculum has been slow to integrate the palliative care course. There was considerable evidence that unprepared nurses reveal anxiety, anguish, and dread when facing dying patients [2]-[4], which compromise patient care quality and patient satisfaction.

Manuscript received August 28, 2020; revised January 14, 2021. This work was supported in part by the Macao Polytechnic Institute under Grant RP/ESS-02/2018.

Yan Wang is with the Macao Polytechnic Institute, 999078, Macao (e-mail: ywang@ipm.edu.mo).
Coping is a term used to describe the process "through which individuals orient their thought and behaviors to solve the origins of stress and manage emotional reactions" [5]. Some studies showed attitudes and coping strategies regarding palliative care can be modulated and enhanced through education [6]. Palliative care actually is a process of coping with dying and death. Nurse educators wanted to improve students' ability to cope with dying and death through education. With limited palliative care practice units and ethical considerations, the palliative care education is predominantly carried out by theoretical lectures which may be complained by both students and educators for lacking in practicing. For example, Berndtsson used a dedicated five-week palliative care course for the year three nursing students. Their courses included 12 lectures: the most common palliative diagnoses, relief from distressing symptoms, ethical issues, care of relatives, physical and mental changes in the dying patient, and the importance of advocating for the patient and their relatives [7]. Jafari used a 4-hour lecture, film, and a group discussion to improve nursing students' attitude. The teaching content included concepts of death and dying, beliefs and feelings about palliative care, physiologic and psychological needs of dying patients, the care for families, and symptoms relief and treatment [8].

Some students admitted that the imagines about death were more frightening than the authentic experience [9]. The experiences gained through simulation may help clarify the imaginary uncertainty. Simulation, as one kind of experiential learning, is now increasingly incorporated into palliative care education. Simulation is defined as "An event or situation made to resemble clinical practice as closely as possible [10]." It provides nursing students with a consistent, safe, and supportive environment to gain the palliative care experience. Simulation-based PC education for undergraduate nursing students varies in hours, methods, and contents worldwide. Most reported palliative care simulations were scenario-centered learning without lectures. These simulations were mainly composed of three parts: preparation, simulation scenario, and debriefing. For example, Dame ran a 15-minute simulation scenario, following by a discussion and sharing meeting to teach the topic of end-of-life care [11]. In Carman's research, participants were e-mailed a link to a recorded lecture on palliative care before the simulation. The lecture included the required readings on fundamental physiologic changes in the dying process, evidence-based measures for symptom management, and nursing care. A 25-minute debriefing 
followed the 20-minute simulation [12]. Venkatasalu used a15-minute introduction for the case, a 20-minute scenario, and a 40-minute debriefing in the palliative care education [13]. Jeffers' research compared the effects of the 6 hours of simulation education with a one-day hospice clinical practice. The 6-hour simulation was composed of reading and assignment preparation, a 20-minute simulation scenario, and debriefing [14].

The literature review shows that most palliative care simulations carried out the scenario without enough knowledge and skill preparations. During the scenario, facing the dying patient and their families, nursing students should not just be encouraged to love and be patient; they should be equipped with professional palliative care knowledge and skills. When they found they could relieve terminal symptoms, supply comfort, ensure dignity, and communicate effectively, the palliative care competencies could finally be gained. Many reported researches have already proved that scenario-based simulation was an excellent bridge to gaps between the learned palliative care knowledge and clinical situations. More emphasis should be transferred to the theoretical and skill preparation before the simulation scenario.

Carman suggested that a combination of theoretical learning in lecture and practical application in the simulation would be an effective way to provide end-of-life preparation [12]. We designed our education interventions as a combination of theoretical lectures with simulation-based scenarios. This research aimed to improve students' knowledge, attitude, and coping with death by an 18-hour palliative care course combining didactic lectures with practical simulation.

\section{METHOD}

This study, adopting a quasi-experimental design, was conducted with a pre-posttest assessment of a single group with three questionnaires.

\section{A. Participants}

Nursing students of Year 2 and 3 from a four-year undergraduate nursing program in a Macao institute were invited to enroll in this research. The research excluded students of Year 1 and 4. Year 1 students who were still learning the basic nursing theory were not ready for palliative care. The Year 4 students who spent most of their time in the clinical rotation could not coordinate with this course schedule. Finally, 52 nursing students enrolled in and finished the 18-hour course.

\section{B. Interventions}

The AACN (American Association of Colleges of Nursing) identified seventeen palliative care competencies that every nursing student must attain before graduation [15]. Our course focused on nine of the AACN (2019) palliative care competencies and classified them into two aspects: 1) caring dying patients and their families (including competency 5, 6, $7,8,10,11,12)$, and 2) self-recognizing/self-coping (including competency 3, 15). Nursing students should be trained to have the competencies of assessing and treating physically, psychologically, socially, and spiritually with evidence-based pharmacologic and non-pharmacologic approaches (competency 7, 10, 11, 12), through effective communication with the patients, patients' families, and the colleagues in the inter-professional team (competency 5, 6, 11 ), and by practicing ethical principles (competency 8). Nursing students also should be trained to identify their own ethical, cultural, and spiritual values and beliefs about death (competency 3) and implement the self-care strategies to cope with suffering, moral distress, and compassion fatigue (competency 15). Our course trained students on the first aspect (caring for dying patients and their families) through lectures and simulation-based scenarios. We trained students on the second aspect (self-recognizing/self-coping) by the debriefing after the simulation scenario.

The 18-hour palliative care course was composed of a 2-hour lecture, a 10-hour lecture-simulation-combined terminal symptom learning (divided into five times), and the 6-hour simulation scenarios practicing (divided into two times). The course lasted for around one month, two times per week. To ensure every student's participation, we divided fifty-two students into five groups, and every group had about ten students. The research ran the 18-hour-course five times, and each time had the same complete contents.

The first 2-hour lecture focused on the basic theories and principles of palliative care. In the next 10 hours, the mechanism, assessment, medications, complementary therapies, and nursing interventions for the terminal symptoms were taught one by one, first by didactic lectures, and then followed students' practicing on manikins to care terminal symptoms while communicating with patients. The terminal symptoms were shown by the high-fidelity manikin together with some pictures and wounds apparatus. Meanwhile, the tutor used the vocal system of the manikin to mimic the patient's voice. The associated terminal symptoms were pain, dyspnea, anorexia, nausea and vomiting, thrush, ascites, intestinal obstruction, and malignant ulcer/fistulae, etc. Tutors merged the communication skills, cultural and spiritual assessment, and interdisciplinary cooperation into 10-hour learning. The last 6 hours were separated into two parts, composed of 3-hour-scenario for non-urgent death while 3-hour-scenario for imminent death. The design was shown in Table I. All learned terminal symptoms were mixed in the scenarios. In the 3-hour scenario, the case was first introduced by educators, and then students were divided into the Patient team, Nurse team, and Family team. Forty-five minutes were used for group discussion. Based on the framework drafted by the tutor, students in the Patient team and Family team detailed the possible interactions between the patient, nurses, and families. Students in the Patient team did not know the details of the scenario, and they just made the nursing care plan according to the background of the patient. Every team picked one student to participate in the role-play. The scenario lasted 60 minutes. One student role-played the patient by manikin's vocal system, the educator controlled the manikin, one student role-played the nurses, and one student role-played the family. The rest students were observers. The scenarios were followed by a 60 -minute debriefing guided by the tutor and attended by all students. In the debriefing, we invited the role-played nurse, 
patient, and family to recall the scenario and share their experiences. The tutor would evaluate the performance of the role-players. The tutor also guided participants to reflect the life-and-death of human beings, helping them to construct a positive attitude.

TABLE I: DESIGN FOR THE SIMULATION SCENARIOS PRACTICING (3 HOURS)

\begin{tabular}{|c|c|c|}
\hline Time & Module & Content \\
\hline $15 \mathrm{~min}$ & Introduction & $\begin{array}{l}\text { The tutor introduced the basic information of the } \\
\text { patient. }\end{array}$ \\
\hline $45 \mathrm{~min}$ & $\begin{array}{l}\text { Group } \\
\text { discussion }\end{array}$ & $\begin{array}{l}\text { Students were divided into three groups (Patient } \\
\text { team, Family team, and Nurse team). } \\
\text { (1)Patients team and Family team: the tutor } \\
\text { drafted the framework of the scenario in } \\
\text { advance; and students in Patient team and } \\
\text { Family team wrote the script, setting the details } \\
\text { in the scenario according to the tutor's guidance; } \\
\text { (2) Nurse team: Discuss the nursing care plan for } \\
\text { the patient and family. }\end{array}$ \\
\hline $60 \mathrm{~min}$ & $\begin{array}{l}\text { Scenario } \\
\text { simulation }\end{array}$ & $\begin{array}{l}\text { (1) Every team selected one student to } \\
\text { participate in the scenario; } \\
\text { (2) The tutor controlled the manikin to act as the } \\
\text { dying patient, and the participating student } \\
\text { from Patient team spoke through the vocal } \\
\text { system of the manikin according to the drafted } \\
\text { script }\end{array}$ \\
\hline $60 \mathrm{~min}$ & Debriefing & $\begin{array}{l}\text { (1) The three participating students shared the } \\
\text { challenges and feelings; } \\
\text { (2) The tutor evaluated students' performance in } \\
\text { the scenario; } \\
\text { (3) The tutor guided all students to reflect on the } \\
\text { hospice care, the nurses' role in hospice care and } \\
\text { their view on life-and-death }\end{array}$ \\
\hline
\end{tabular}

\section{Instrument}

Firstly, participants' demographic information, including grade, gender, the experience of caring for dying patients, were collected. The Palliative Care Quiz for Nursing (PCQN) was used to examine the palliative care knowledge. It was a 20-items scale, including philosophy and principles (4 items), pain and symptom management (13 items), and psychosocial and spiritual aspects (3 items). Students choose "true," "false," or "don't know" for each item, and the total score is gained by calculating the number of correct responses. The total scores range from 0 to 20 , with higher scores corresponding to higher palliative care knowledge levels. The validity of PCQN was confirmed during its development with an acceptable alpha of 0.78 [16].

The Frommelt Attitude towards Care of the Dying (FATCOD) scale was used to assess students' attitudes towards caring for dying patients [17]. The items were divided into the patient-centered and family-centered dimensions. It has been tested and validated in several countries with different cultures, such as Japan [18] and Sweden [19]. It consists of 30 items using a 5-point Likert scale. The scores range from 30 to 150 , with higher scores representing a more positive attitude for caring for the dying patient and his families. The reported internal consistency of the FATCOD was alpha $=0.81$ [20]. The reported inter-rater agreement was 1.00 [17].

Coping with Death Scale (CDS) was initially developed by Bugen to measure the benefits of a death education through the participants' sense of competency in palliative care. It comprises 30 items using a 7-point Likert scale. The score ranges from 30 to 210 , with higher scores representing a better coping competency for death. The items are organized into two factors: coping with death and coping with others' death. The scale showed an adequate level of internal consistency with Cronbach's alpha of 0.89 [21].

\section{ETHICAL CONSIDERATIONS}

Informed consent was obtained from all participants. Participants have been informed of voluntary participation, and they could withdraw from the research at any time without penalty. The name and personal data of all participants were kept confidential by coding numbers. Institutional review board approval was obtained.

\section{DATA ANALYSIS}

The obtained data were analyzed using the statistical analyzing program SPSS (version 26). A paired $t$-test was used to examine the presence of statistically significant differences in the mean PCQN, FATCOD, and CDS scores between the pre-and-post variables. Multiple regression analysis with the entry method was used to examine the relationship between the variables with coping with the death of Macao nursing students.

\section{RESUlts}

\section{A. Characteristics of Nursing Students}

There were $15(28.8 \%)$ male and $37(71.2 \%)$ female nursing students involved in this research. There were 23 (44.2\%) students from Year 2, while 29 (55.8\%) students from Year 3. Thirty $(57.7 \%)$ students had the experience of caring for dying patients during their clinical rotation, while $22(42.3 \%)$ students did not have the experience of caring for dying patients.

\section{B. Palliative Care Knowledge}

The pre-mean score of PCQN was 8.98 (SD 2.46), with scores ranging from 4 to 13 . The post-mean score of PCQN was 12.98 (SD 2.47), with scores ranging from 8 to 18 . Twenty-two participants $(42.3 \%)$ answered at least $50 \%$ of the questions correctly before the education, whereas forty-seven $(90.4 \%)$ answered at least $50 \%$ of the questions correctly after the education. Table II shows the sub-total scores before and after the workshop for each dimension. Before the workshop, the "philosophy and principles of palliative care" dimension earned a mean score of 1.62 (SD 0.89 , range $=0-3)$, the "pain and symptoms management" dimension earned a mean score of 6.23 (SD 1.58, range $=0-13$ ), and the "psychosocial and spiritual care" dimension earned a mean score of 1.13 (SD 2.46, range=0-4). The mean score after the workshop was 2.38 (SD 0.89), 8.78 (SD 1.40), and 1.85 (SD 0.72), respectively. Students' palliative care knowledge was improved after the course in the dimensions of philosophy and principles $(P<0.05)$, pain and symptoms management $(P<0.05)$, and psychosocial and spiritual care $(P<0.05)$. (See Table II)

\section{Palliative Care Attitude}

The pre and post mean scores of FATCOD were 108.92 
(SD 7.40) and 119.37 (SD 8.57), respectively. Before the workshop, the "patient-centered" dimension earned a mean score of 70.37 (SD 5.92), and the "family-centered" dimension earned a mean score of 38.56 (SD 2.61). The mean score after the workshop was 78.88 (SD 6.84) and 40.48 (SD $2.30)$, respectively. Students' palliative care attitude was improved after the intervention $(P<0.05)$. The differences between pre score and post score in both the patient-centered dimension and family-centered showed statistical significance $(P<0.05)$ (Table III).

TABLE II: DIFFERENCES OF THE PCQN BETWEEN PRE- AND POST-TEST $(N=52)$

\begin{tabular}{|c|c|c|c|c|c|c|}
\hline \multirow[t]{2}{*}{ Dimensions } & \multicolumn{2}{|c|}{ Pre-test } & \multicolumn{2}{|c|}{ Post-test } & \multirow[b]{2}{*}{$t$} & \multirow[b]{2}{*}{$P$} \\
\hline & Mean & SD & Mean & $\mathrm{SD}$ & & \\
\hline $\begin{array}{l}\text { Philosophy and } \\
\text { principles }\end{array}$ & 1.62 & 0.89 & 2.38 & 0.89 & -6.492 & .000 \\
\hline $\begin{array}{l}\text { Pain and } \\
\text { symptom } \\
\text { management }\end{array}$ & 6.23 & 1.58 & 8.75 & 1.40 & -14.073 & .000 \\
\hline $\begin{array}{l}\text { Psychosocial and } \\
\text { spiritual }\end{array}$ & 1.13 & 0.77 & 1.85 & 0.72 & -5.892 & .000 \\
\hline Total score & 8.98 & 2.46 & 12.98 & 2.47 & -17.535 & .000 \\
\hline
\end{tabular}

TABLE III: DIFFERENCES OF THE FATCOD BETWEEN PRE- AND POST-TEST $(N=52)$

\begin{tabular}{|c|c|c|c|c|c|c|}
\hline \multirow[t]{2}{*}{ Dimensions } & \multicolumn{2}{|l|}{ Pre-test } & \multicolumn{2}{|c|}{ Post-test } & \multirow[b]{2}{*}{$t$} & \multirow[b]{2}{*}{$P$} \\
\hline & Mean & SD & Mean & SD & & \\
\hline Patient-centered & 70.37 & 5.92 & 78.88 & 6.84 & -18.457 & .000 \\
\hline Family-centered & 38.56 & 2.61 & 40.48 & 2.30 & -7.937 & .000 \\
\hline Total score & 108.92 & 7.40 & 119.37 & 8.57 & -24.126 & .000 \\
\hline
\end{tabular}

\section{Coping With Death}

The pre and post mean scores of CDS were 125.33 (SD 18.54, range=76-163) and 145.25 (SD 16.78, range= 102-170), respectively. Before the workshop, the "coping with death" dimension earned a mean score of 17.92 (SD $3.85)$, the "coping with others' death" dimension earned a mean score of 36.81 (SD 6.15), and the "coping with self's death" dimension earned a mean score of 70.60 (SD 11.55). The mean scores after the course were 19.15 (SD 4.08), 43.75 (SD 5.68), and 82.35 (SD 10.28), respectively. Students' coping with death was improved after the intervention in the dimensions of coping with self's death $(P<0.05)$, coping with others' death $(P<0.05)$, and coping with death $(P<0.05)$ (Table IV).

\section{E. Predictor of Nursing Students' Coping with Death}

The results of multiple regression with the entry method are presented in Table V. "Gender," "grade, "and "experience of caring for dying patients" were not associated with coping with death $(P>0.05)$. The scores of PCQN and FATCOD predicted $83.6 \%$ variance in CDS scores. The positive coefficients indicated that the palliative care knowledge and attitude had positive effects on nursing students' coping with death.

\section{DISCUSSION}

\section{A. Palliative Care Knowledge}

Palliative care knowledge deficit among nurses is one of the main obstacles in providing high-quality palliative care 。 Nurses' knowledge deficit might originate from insufficient education during their undergraduate learning. Palliative care knowledge mainly includes ethical principles and terminal symptoms management (mechanism, assessment, medications, and supplementary treatment). Participates gained 8.98 (SD 2.46) in PCQN at the baseline. The low mean score of PCQN before the course showed inadequate palliative care knowledge in Macao nursing undergraduate students. Previous studies conducted worldwide reported similar results that baseline knowledge assessments evidenced students' deficiency. In Al Qadire's research, 220 Jordan nursing students were investigated for their palliative care knowledge. The results showed a low level of knowledge (mean=8 out of 20; SD 3.1) [22]. Another study conducted by Chari indicated average poor knowledge of palliative care in final-year students of the undergraduate nursing program. The same result was found in India's research [23]. Ahmad E surveyed in Saudi Arabia in 409 nursing students, got a mean score of 5.23 out of 20 (SD 3.24) [24]. Dimoula surveyed 529 Greek nursing students, gain a mean score of 8.2 (SD 2.8) [20].

The results showed a statistically significant improvement in palliative care knowledge after the course by 4 points in the total score. All dimensions in the PCQN showed positive changes. For example, the changed score of Q1, which belongs to the philosophy and principles dimension, showed the correction of the misunderstanding that palliative care was only for the person who was very near death. We emphasized the principle of palliative care in the first 2-hour lecture that palliative care should begin at the beginning of diagnosing a terminal disease. Q3, Q7, and Q13 were about symptom control. To control and to relieve the terminal symptom was the focus in the 10-hour simulation-based learning. We taught students that medication rules should be adjusted in palliative care, focusing on pain-relieving rather than drug addiction. Most participants thought families' accompany until the patient's death was crucial (Q5). In the workshop, we emphasized that families should be included in psychosocial caring, and nurses should try to help families avoid severe suffering and tortures that might last for the rest of their life. After the course, most students accepted the facing death may be avoided to control the irritating for families.

\section{B. Palliative Care Attitude}

Attitudes are formed as a result of a favorable or unfavorable evaluation of a particular entity. Feeling useless and unable to help the dying patients and their families could accumulate into negative attitudes towards palliative care. Exposure to patients' dying processes might remind nurses of their mortality, which may negatively affect palliative care. Frommelt developed the FATCOD in 2003 to evaluate the effects of an education program. The results showed students developed more positive attitudes, as evidenced by improvement in a mean score of 118 at the pre-test while 129.8 at post-test (Frommelt, 2003). Since then, the FATCOD has been widely used in research with nurses and the undergraduate nursing student population. Great differences were found in the palliative care attitude of nursing students gaining through FATCOD. The reported mean score was 123 (SD 10.1) in Sweden, 95.81 (SD 8.03) in India [25], 96.96 (SD 8.30) in Palestine [26] 93.83 (SD 5.96) 
in Indonesia [27], and 111.9 (SD 10.2) in Greece [20]. Compared with other countries, Macao's score was in the middle class with a pre-test score of 108.92 (SD 7.40).

TABLE IV: DIFFERENCES OF THE CDS BETWEEN PRE- AND POST-TEST

\begin{tabular}{|c|c|c|c|c|c|c|c|c|c|c|c|}
\hline \multicolumn{2}{|c|}{$\begin{array}{l}\text { TABLE IV: DIFFERENCES OF THE CDS B } \\
\qquad(N=52)\end{array}$} & $\mathrm{EN} P R$ & $\mathrm{DPO}$ & & \multicolumn{3}{|l|}{ Total } & 125.33 & 145.25 & -23.70 & .000 \\
\hline Item & $\begin{array}{l}\text { Pre } \\
\text { mean } \\
\text { score }\end{array}$ & $\begin{array}{l}\text { Post } \\
\text { mean } \\
\text { score }\end{array}$ & $t$ & $P$ & \multicolumn{7}{|c|}{$\begin{array}{l}\text { TABLE V: PREDICTORS OF COPING WITH THE DEATH OF THE NURSING } \\
\text { STUDENTS }(N=52)\end{array}$} \\
\hline Coping with the death & 17.92 & 19.15 & -3.85 & .000 & Variables & $\mathrm{B}$ & S.E. & Beta & $\mathrm{T}$ & $P$ & VIF \\
\hline Q1: Thinking about death is a & 5.29 & 6.04 & -5.37 & .000 & & & & & & & \\
\hline waste of time. & & & & & Gender & 3.129 & 2.250 & .085 & 1.391 & .171 & 1.173 \\
\hline Q2: I have a good perspective & 4.56 & 5.65 & -5.42 & .000 & Grade & -3.491 & 2.542 & -.104 & -1.373 & .176 & 1.800 \\
\hline on death and dying. & & & & & Experience of & 3.902 & 2.584 & .116 & 1.510 & .138 & 1.840 \\
\hline $\begin{array}{l}\text { Q3: Death is an area that can be } \\
\text { dealt with safely. }\end{array}$ & 5.67 & 6.23 & -5.01 & .000 & $\begin{array}{l}\text { caring for } \\
\text { dying patients }\end{array}$ & & & & & & \\
\hline Q4: I am aware of the full array & 3.42 & 3.69 & -1.57 & .123 & PCQN & 3.327 & .762 & .490 & 4.365 & .000 & 3.922 \\
\hline of services from funeral homes. & & & & & FATCOD & .879 & .224 & .437 & 3.920 & .000 & 3.878 \\
\hline
\end{tabular}

options for disposing of bodies.

Q6: I am aware of the full arra

of emotions that characterize

human grief.

Q11: I am familiar with

prearrangement of funerals.

Q12: Lately I find it OK to

think about death.

Q13: My attitude about living

has recently changed.

Q30: I can tell someone, before

I or they die, how much I love them

Coping with others' death

Q21: I feel able to handle the

death of others close to me.

Q22: I know how to listen to

others, including the terminally

ill.

Q23: I know how to speak to

children about death.

Q24: I may say the wrong thing

when I am with someone

mourning.

Q25: I am able to spend time

with the dying if I need to.

Q26: I can help someone with

their thoughts and feelings

about death and dying.

Q27: I would be able to talk to a

friend or family member about

their death.

Q28: I can lessen the anxiety of

those around me when the topic

is death and dying.

Q29: I can communicate with the dying.

Coping with self's death

Q7: Knowing that I will surely

die does not in any way affect

the conduct of my life.

Q8: I feel prepared to face my

death.

Q9: I feel prepared to face my

dying process.

Q10: I understand my

death-related fears.

Q14: I can express my fears

about dying.

Q15: I can put words to my

gut-level feelings about death and dying.

Q16: I am making the best of

my present life.

Q17: The quality of my life

matters more than the length of

it.

Q18: I can talk about my death with family and friends.

Q19: I know who to contact

when death occurs.

$\begin{array}{lllll}\text { Q20: I will be able to cope with } \quad 4.40 & 5.23 & -5.83 & .000\end{array}$ future losses.
Attitudes are expected to change over time and with experience. Our study shows a statistically significant positive change in palliative care attitude after the course by 10.45 points. This result is in line with Berndtsson's finding that the mean score increased by 9.6 points after a dedicated five-week course, including 12 lectures [7]. Also, Henoch improved nursing students' attitudes by 6 points after five weeks of palliative care theoretical education [17]. Considering the patient-centered items, for example, most students reported difficulties in communication. Still, after the course, students gained higher scores in talking about the impending death with patients (Q3) and finding it easier to form a close relationship with the dying person (Q9). Before the course, students might be hard to accept the words "death welcomed by the dying (Q10)". After the course, more students chose a neutral attitude to this statement. In the simulation, we set a scenario requiring the nursing to discuss with patients' families whether the honest answer should be given in response to the patient's asking. The role-played nurse chose to support the idea of being honest with the patient in the scenario. The student explained and sharing her thoughts and behaviors in the debriefing, which aroused hot discussion. Accordingly, we found a positive change in Q27. Regarding the family-centered dimension, students become more understand that caring for families should be carried throughout the whole caring period (Q7). Our course was proved to correct the misunderstanding that at the very last stage of the patient dying process, nurses need to withdraw and let families stay with the patient solely (Q17). Students have always been alert to families because of pressure. After the course, students become more acceptable about the families' anxiety and would not regard them as an interference to the treatments (Q29).

\section{Coping}

Education could improve students' coping, but little research was focused on students' coping in palliative care. If the students have mastered the knowledge, practiced skills, and experienced the dying situation through simulation-based practice, they may gain the confidence in their abilities to respond correctly to such situations and use active coping strategies. Most students confessed their awareness of that avoidance of death was impossible. Caring the dying did not mean to stop or postpone death. Trying to 
be useful to relieve the pain and comfort the sufferings may be the best way to cope. The results of our research showed a statistically significant improvement in students' coping with death. We group the items in CDS into three dimensions. "Coping with the death" means the coping for the death of all human beings. "Coping with others' death" focuses on the students' abilities to care for dying patients. "Coping with self's death" means the ability to deal with the participant's own death affairs.

The changes in the scores of the first dimension showed students began to think about death. Not-avoiding-thinking was already progressing for coping. But the scores of Q4, Q5, and Q6 showed our education was insufficient in the affairs after death. All the questions about coping with others' death had been improved by the intervention. We believed the idea of one's death is the roots of the nurses' palliative care, so students were encouraged in the debriefing to discuss the feeling and possibilities about their death. We found Q16 does not show differences between the pre and post scores, which means students already accepted before the course that the quality of life matters more than the length of it before the course.

Little research was found to research the predictors for nursing students' coping with death. From this research, we found students' gender, grade, and the experience of caring for dying patients were not predictors for coping with death. The knowledge and the attitude on the palliative care could explain the $83.2 \%$ variance of students' coping death, which gave educators a hint to enable nursing students in palliative care by improving their palliative care knowledge and attitude.

\section{LIMITATION}

Some limitations were identified in this study. Firstly, a small convenience sample from a single institution limits the generalizability of the research findings. Secondly, only self-reported data were used, which may cause response bias. Finally, the limited sample volume made it impossible to carry out the factor analysis for CDS.

\section{CONCLUSIONS}

This research showed a picture of Macao nursing students' palliative care knowledge, palliative care attitude, and coping with death. The poor baseline evaluation suggests a lecture-simulation-combined course should be a mandatory part of the nursing curriculum. This study strongly supports that palliative care education, which combined didactic lectures with simulation-based scenario practices, was an effective method to improve Macao nursing students' palliative care knowledge, palliative care attitude, and coping with death. With increased knowledge and improved attitude, nursing students are expected to have positive coping, which will benefit their future professional and personal career. It is recommended that future studies may need to include more objective variables to evaluate students' gaining from palliative care education. Furthermore, bigger sample size may enable factor analysis.

\section{CONFLICT OF INTEREST}

The authors declare that there are no conflicts of interests regarding the publication of this paper.

\section{AUTHOR CONTRIBUTIONS}

Yan Wang is responsible for designing and conducting the research, analyzing the data, and writing this article.

\section{REFERENCES}

[1] M. B. Smith, T. G. R. Macieira, and M. D. Bumbach, "The use of simulation to teach nursing students and clinicians palliative care and end-of-life communication: A systematic review," Am. J. Hosp. Palliat Care, vol. 35, no. 8, pp. 1140-54, 2018.

[2] S. G. Rodrigues, "Tradução e validação da escala de coping com a morte: Um estudo com enfermeiros," Revista De Enfermagem Referência, vol. 7, pp. 113-122, 2015.

[3] J. D'Antonio, "End-of-life nursing care and education: Past and present," Journal of Christian Nursing, vol. 34, no. 1, pp. 34-38, 2017.

[4] R. Cant and S. Cooper, "The value of simulation-based learning in pre-licensure nurse education: A state-of-the-art review and meta-analysis," Nurse Education in Practice, vol 27, pp. 45-62, 2017.

[5] R. Lazarus, "Coping with the stress of ilness," Health Promotion and Chronic Illness: Discovering a New Quality of Health, Copenhagen: WHO, Regional Office for Europe, 1993, pp. 11-29.

[6] C. C. Barrere, A. Durkin, and S. LaCoursiere, "The influence of end-of-life education on attitudes of nursing students," Int J Nurs Educ Scholarsh, vol. 5, article11, 2008.

[7] K. E. Berndtsson, K. G. Margareta, and RejnöC.U.Åsa, "Nursing students' attitudes toward care of dying patients: A pre- and post-palliative course study," Heliyon, vol. 5, no. 10, p. E02578, 2019.

[8] M. Jafari, H. H. Rafiei, A. Nassehi, F. Soleimani, M. Arab, and M. Noormohammadi, "Caring for dying patients: Attitude of nursing students and effects of education," Indian Journal of Palliative Care, vol. 21, no. 2, pp. 192-197, 2015.

[9] E. K. Kristina, L. Westin, C. Prahl, J. Österlind, S. Strang, I. Bergh, and K. Hammarlund, "Death and caring for dying patients: Exploring first-year nursing students' descriptive experiences," International Journal of Palliative Nursing, vol. 20, no. 10, pp. 509-515, 2014.

[10] P. Jeffries, "National league for nursing," Simulation in Nursing Education: From Conceptualization to Evaluation, 2nd ed. New York, 2012, NY: National League for Nursing, p. 168.

[11] L. Dame and R. Hoebeke, "Effects of a simulation exercise on nursing students' end-of-Life care attitudes," The Journal of Nursing Education, vol. 55, no. 12, pp. 701-705, 2016.

[12] J.M. Carman, R. Sloane, M. Molloy, E. Flint, and B. Phillips, "Implementation of a learning bundle to promote end-of-life education for prelicensure nursing students," Journal of Hospice \& Palliative Nursing, vol. 18, no. 4, pp. 356-363, 2016.

[13] M. Venkatasalu, M. Kelleher, and C. Shao, "Reported clinical outcomes of high-fidelity simulation versus classroom-based end-of-life care education," International Journal of Palliative Nursing, vol. 21 , no. 4 , pp. 179-186, 2015.

[14] S. Jeffers, "Integration of a hospice clinical experience: Nursing students' perceptions," Journal of Hospice \& Palliative Nursing, vol. 20, no. 3, pp. 266-271, 2018.

[15] American Association of Colleges of Nursing (2019). Competencies and recommendations for education undergraduate nursing students preparing nurses to care for the seriously ill and their families. [Online]. Available:

https://www.mypcnow.org/wp-content/uploads/2019/03/New-Nursing -Palliative-Care-Competencies.pdf

[16] M. M. Ross, B. McDonald, and J. McGuinness, "The palliative care quiz for nursing (PCQN): The development of an instrument to measure nurses," Journal of Advanced Nursing, vol. 23, pp. 126-137, 1996.

[17] H. K. Frommelt, "Attitudes toward care of the terminally ill: An educational intervention," AM J Hosp Palliat Care, vol. 20, no. 1, pp. 13-22, 2003.

[18] M. Matsui, E. Kanai, A. Kitagawa, and K. Hattori, "Care managers' views on death and caring for older cancer patients in Japan," International Journal of Palliative Nursing, vol. 19, no. 12, pp. 606-611, 2013.

[19] I. Henoch, C. Melin-Johansson, and I. Bergh, "Undergraduate nursing students' attitudes and preparedness toward caring for dying persons - 
A longitudinal study," Nurse Education in Practice, vol. 26, pp. 12-20, 2017.

[20] M. Dimoula, G. Kotronoulas, S. Katsaragakis, M. Christou, S. Sgourou, and E. Patiraki, "Undergraduate nursing students' knowledge about palliative care and attitudes towards end-of-life care: A three-cohort, cross-sectional survey," Nurse Education Today, vol. 74, pp. 7-14, 2019.

[21] R. Robbins, "Bugen's coping with death scale: Reliability and further validation," Omega - Journal of Death and Dying, vol. 22, no. 4, pp. 287-299, 1990.

[22] M. Al Qadire, "Nurses' knowledge about palliative care: A cross-sectional survey," Journal of Hospice \& Palliative Nursing, vol. 16, no. 1, pp. 23-30, 2014.

[23] S. Chari, M. Gupta, M. Choudhary, and L. Sukare, "Knowledge and attitude of nursing students towards palliative care: Role of focused training," Int Jour of Biomed Res, vol. 7, no. 9, pp. 629-632, 2016.

[24] E.A. Aboshaiqah, "Predictors of palliative care knowledge among nursing students in Saudi Arabia: A cross-sectional study," Journal of Nursing Research, vol. 28, no. 1, pp. E60, 2020.

[25] S. Paul, G. Renu, and P. Thampi, "Creating a positive attitude toward dying patients among nursing students: Is the current curriculum adequate?" Indian Journal of Palliative Care, vol. 25, no. 1, pp. 142-146, 2019.
[26] N. I. Abu-El-Noor and M. K. Abu-El-Noor, "Attitude of palestinian nursing students toward caring for dying patients: A call for change in health education policy," J Holist Nurs, vol. 34, no. 2, pp.193-9, Jun 2016.

[27] Z. Muhamad, S. Baskoro, and K. E. Dicky, "Nursing students' attitudes towards caring for dying patients," Nurse Media: Journal of Nursing, vol. 8, no. 1, pp. 25-34, 2018.

Copyright (C) 2021 by the authors. This is an open access article distributed under the Creative Commons Attribution License which permits unrestricted use, distribution, and reproduction in any medium, provided the original work is properly cited (CC BY 4.0).

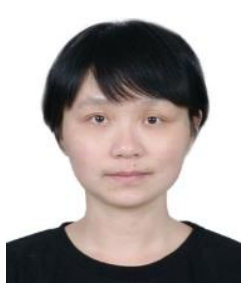

Yan Wang was born in Chong Qing, China on October 28, 1976. She graduated with a bachelor of nursing science from the West China University of Medical Science in 2000. Then she gained the master's degree in nursing science from $\mathrm{Si}$ Chuan University in 2003, and Ph.D in public health from Macao University of Science and Technology in 2013. Currently she is working as a lecture at Macao Polytechnic Institute, Macao. Her research fields include nursing ethics, evidence-based nursing, palliative care, and life-and-death education. 